\title{
Prognostic Implications of Chronic Kidney Disease on Patients Presenting with ST-Segment Elevation Myocardial Infarction with versus without Stent Thrombosis
}

\author{
Gilad Margolis Shahar Vig Nir Flint Shafik Khoury Michael Barkagan \\ Gad Keren Yacov Shacham \\ Department of Cardiology, Tel Aviv Sourasky Medical Center Affiliated to the Sackler \\ Faculty of Medicine, Tel Aviv University, Tel Aviv, Israel
}

\section{Keywords}

Acute myocardial infarction - Percutaneous coronary intervention · Stent thrombosis .

Chronic kidney disease $\cdot$ Mortality

\begin{abstract}
Background: Limited data is present regarding long-term outcomes in chronic kidney disease (CKD) patients presenting with stent thrombosis (ST). We evaluated the possible implications of CKD on long-term mortality in patients presenting with ST-segment elevation myocardial infarction (STEMI) and treated with primary percutaneous coronary intervention (PCI), and its interaction with the presence of ST. Methods: We retrospectively studied 1,722 STEMI patients treated with primary PCI. Baseline CKD was categorized as an estimated glomerular filtration rate $<60 \mathrm{~mL} / \mathrm{min} / 1.73 \mathrm{~m}^{2}$ at presentation. The presence of ST was determined using the Academic Research Consortium definitions. Patients were evaluated for the presence of CKD and ST, as well as for long-term mortality. Results: A total of 448/1,722 (26\%) patients had baseline CKD. Patients with CKD were older and had more comorbidities and a higher rate of ST (4 vs. $7 \%$, respectively, $p<0.001$ ). In a univariate analysis, long-term mortality was significantly higher among those with CKD compared to those without CKD (17.6 vs. $2.7 \%, p<0.001)$. The presence of ST did not alter long-term mortality in both CKD and no-CKD patients. In a Cox regression model, CKD was an independent predictor of long-term mortality (hazard ratio $2.04,95 \%$ confidence interval $1.17-3.56, p=0.01$ ), while ST as a covariate was not significantly associated with long-term mortality. Conclusion: Among STEMI patients, CKD, but not ST, is a predictor of long-term mortality.

(c) 2017 S. Karger AG, Basel
\end{abstract}

Drs. Margolis and Vig contributed equally to this work. 


\section{CardioRenal Medicine}

\begin{tabular}{l|l}
\hline Cardiorenal Med 2017;7:150-157 \\
\hline DOI: 10.1159/000455905 & $\begin{array}{l}\text { @ 2017 S. Karger AG, Basel } \\
\text { www.karger.com/crm }\end{array}$ \\
\hline
\end{tabular}

Margolis et al.: Prognostic Implications of Chronic Kidney Disease on Patients Presenting with STEMI with versus without Stent Thrombosis

\section{Introduction}

Chronic kidney disease (CKD) is associated with an increased risk for coronary artery disease (CAD) and unfavorable cardiovascular outcomes [1-3]. Among patients with myocardial infarction treated with percutaneous coronary intervention (PCI), CKD is a wellestablished predictor for in-hospital complications and mortality as well as for long-term mortality [4-7]. Stent thrombosis (ST) is a dreaded complication of PCI associated with high morbidity and mortality [8-10]. CKD was implicated as a risk factor for ST by various investigators [9-13] with an observed higher magnitude of on-treatment platelet reactivity among CKD patients cited as a possible mechanism for this interaction [14, 15]. Very few reports, however, evaluated the possible impact of CKD on the prognosis of patients who suffered an ST event and those who did produced conflicting results $[16,17]$. In the present study, we evaluated the possible implications of CKD on long-term survival of a large cohort of patients who presented with ST-segment elevation myocardial infarction (STEMI) due to ST or de novo coronary thrombosis and were treated with primary PCI.

\section{Materials and Methods}

\section{Study Population}

A retrospective, single-center observational study was performed at the Tel Aviv Sourasky Medical Center, a tertiary referral hospital with a $24 / 7$ primary PCI service as described previously $[18,19]$. Eligible were all 1,824 consecutive patients admitted between January 2008 and December 2014 to the cardiac intensive care unit with the diagnosis of acute STEMI. Excluded were patients treated either conservatively or by thrombolysis $(n=31)$, as were 70 patients whose final diagnosis on discharge was other than STEMI (e.g., myocarditis or Takotsubo cardiomyopathy) and 1 patient whose serum creatinine levels at admission was not known. The final study population included 1,722 patients whose baseline demographic features, cardiovascular history, clinical risk factors, treatment characteristics, and laboratory results were retrieved from their hospital electronic medical files. The study protocol was approved by the local institutional ethics committee.

\section{Study Protocol}

The diagnosis of STEMI was established in accordance to published guidelines including a typical history of chest pain, diagnostic electrocardiographic changes, and serial elevation of serum cardiac biomarkers [20]. Primary PCI was performed in patients with symptoms $\leq 12 \mathrm{~h}$ in duration as well as in patients with symptoms lasting $12-24 \mathrm{~h}$ in duration if the symptoms continued to persist at the time of the admission. Left ventricular ejection fraction (LVEF) was measured in all patients, by bedside echocardiography, within the first $48 \mathrm{~h}$ of admission. Patient records were evaluated for baseline variables. Long-term mortality was assessed over a mean period of 1,170 \pm 784 days (range 1-2,736) up to March 31, 2015. Assessment of survival following hospital discharge was performed from computerized records of the population registry bureau.

Serum creatinine level was determined upon hospital admission and at least once a day during the cardiac intensive care unit stay and was available for all analyzed patients. The estimated glomerular filtration rate (eGFR) was estimated using the abbreviated Modification of Diet in Renal Disease (MDRD) equation [21] using baseline serum creatinine levels. Baseline CKD was categorized as an eGFR $<60 \mathrm{~mL} / \mathrm{min} / 1.73 \mathrm{~m}^{2}$ at presentation and stratified to CKD stage 3 (eGFR $<60 \mathrm{~mL} / \mathrm{min} / 1.73 \mathrm{~m}^{2}$ and $\geq 30 \mathrm{~mL} / \mathrm{min} / 1.73 \mathrm{~m}^{2}$ ) and CKD stage $4 / 5$ (eGFR $<30 \mathrm{~mL} / \mathrm{min} / 1.73 \mathrm{~m}^{2}$ ) according to current guidelines [22].

The presence of ST was determined using the Academic Research Consortium (ARC) definitions [23]. Briefly, definite ST required angiographic confirmation of a thrombus that stems from the stent or from the segment $5 \mathrm{~mm}$ proximal or distal to the stent. A nonocclusive intracoronary thrombus was defined as a noncalcified filling defect or lucency surrounded by contrast material (on 3 sides or within a coronary stenosis) seen in multiple projections, or persistence of contrast material within the lumen, or a visible embolization of intraluminal material downstream. An occlusive thrombus diagnosis required a TIMI 0 or TIMI 1 intra-stent or proximal to a stent up to the most adjacent proximal side branch or main branch. Only patients with definite ST (occlusive or nonocclusive) were included to the ST subgroup. We then performed a subgroup 
Margolis et al.: Prognostic Implications of Chronic Kidney Disease on Patients Presenting with STEMI with versus without Stent Thrombosis

Table 1. Baseline characteristics of patients presenting with and without CKD

\begin{tabular}{lccc}
\hline \multirow{2}{*}{ Variable } & \multicolumn{2}{l}{ CKD } & \multirow{2}{*}{$p$} \\
\cline { 2 - 3 } & no $(n=1,274)$ & yes $(n=448)$ & \\
\hline Age, years & $57 \pm 10.1$ & $75 \pm 10.3$ & $<0.001$ \\
Male gender & $1,049(82)$ & $339(75)$ & $<0.01$ \\
Diabetes mellitus & $251(20)$ & $131(29)$ & $<0.001$ \\
Hypertension & $461(35)$ & $289(63)$ & $<0.001$ \\
Hyperlipidemia & $583(46)$ & $236(52)$ & 0.03 \\
History of smoking & $711(56)$ & $146(32)$ & $<0.001$ \\
Family history of CAD & $273(21)$ & $30(6)$ & $<0.001$ \\
Prior MI & $135(10)$ & $70(15)$ & $<0.001$ \\
Number of narrowed coronary arteries & & & $<0.001$ \\
$\quad 1$ & $584(46)$ & $166(38)$ & 0.43 \\
$\quad 2$ & $385(30)$ & $126(28)$ & $<0.001$ \\
$\quad 303(24)$ & $1.05 \pm 0.15$ & $151(34)$ & $<0.001$ \\
Admission sCr, mg/dL & $80.5 \pm 14.5$ & $1.41 \pm 0.43$ & $<0.001$ \\
eGFR, mL/min/1.73 m ${ }^{2}$ & $48 \pm 7.7$ & $48 \pm 9$ & $<0.001$ \\
LVEF, \% & $815(322-1,651)$ & $719(291-1,579)$ & 0.08 \\
Peak CPK, U/L & $3.9(1.3-10.3)$ & $5.2(1.7-14.4)$ & $<0.01$ \\
Admission CRP, mg/dL & $51(4)$ & $33(7)$ & $<0.001$ \\
ST & & & \\
\hline
\end{tabular}

Variables are $n(\%)$, mean \pm standard deviation, or median (interquartile range). $p<0.05$ is considered significant. CKD, chronic kidney disease; CAD, coronary artery disease; $\mathrm{MI}$, myocardial infarction; $\mathrm{sCr}$, serum creatinine levels; eGFR, estimated glomerular filtration rate; LVEF, left ventricular ejection fraction; CPK, creatine phosphokinase; CRP, C-reactive protein; ST, stent thrombosis.

analysis of the ST subgroup stratified in accordance to the presence of CKD, by assessing the following variables: ARC-defined timing strata [23] - early ST (including patients with acute/subacute ST [within 30 days of stent implantation]), and late ST (including patients with late [between 31 and 365 days of stent implantation], or very late ST [beyond 365 days of stent implantation]), dual antiplatelet therapy (DAPT) treatment at admission, original stent type (bare-metal stent vs. drug-eluting stent), LVEF, culprit ST lesion sites, and bifurcation lesions.

\section{Statistical Analysis}

All data were summarized and displayed as mean \pm standard deviation or median (25-75\%) for continuous variables and as number of patients (\%) in each group for categorical variables. Continuous variables were compared using independent sample $t$ or Mann-Whitney tests. Categorical variables were compared using $\chi^{2}$ square test or Fisher's exact test. The Kaplan-Meier and log-rank tests were used to evaluate the unadjusted effect of CKD and ST on patients' long-term survival. The influence of CKD and ST on the occurrence of all-cause mortality was evaluated using multivariate Cox regression and adjusted for age, gender, hypertension, diabetes mellitus, CAD severity, LVEF, and the presence of ST. A 2-tailed $p<0.05$ was accepted as statistically significant for all analyses. All analyses were performed with the SPSS 23.0 software (SPSS Inc., Chicago, IL, USA).

\section{Results}

A total of 1,722 STEMI patients treated by primary PCI were enrolled in the study, 448 (26\%) of whom had CKD. Among these patients, 426 (95\%) had stage 3 CKD and 22 (5\%) had stage 4/5 CKD. The baseline demographic, clinical, and laboratory findings of the patient population are presented in Table 1. Patients with CKD were older and more likely to be of 


\section{CardioRenal Medicine}

Table 2. Subgroup analysis of ST patients presenting with and without CKD

\begin{tabular}{|c|c|c|c|}
\hline \multicolumn{4}{|c|}{ Cardiorenal Med 2017;7:150-157 } \\
\hline \multicolumn{2}{|l|}{ DOI: $10.1159 / 000455905$} & \multicolumn{2}{|c|}{$\begin{array}{l}\text { (c) } 2017 \text { S. Karger AG, Basel } \\
\text { www.karger.com/crm }\end{array}$} \\
\hline \multicolumn{4}{|c|}{$\begin{array}{l}\text { Margolis et al.: Prognostic Implications of Chronic Kidney Disease on Patients } \\
\text { Presenting with STEMI with versus without Stent Thrombosis }\end{array}$} \\
\hline \multirow[t]{2}{*}{ Variable } & \multicolumn{2}{|l|}{ CKD } & \multirow[t]{2}{*}{$p$} \\
\hline & $\begin{array}{l}\text { no } \\
(n=51)\end{array}$ & $\begin{array}{l}\text { yes } \\
(n=33)\end{array}$ & \\
\hline Female gender & $4(8)$ & $8(23)$ & 0.04 \\
\hline Early ST & $20(39)$ & $15(45)$ & 0.65 \\
\hline Late ST & $31(61)$ & $18(55)$ & 0.65 \\
\hline DAPT & $14(27)$ & $11(33)$ & 0.62 \\
\hline LVEF, \% & $46 \pm 10.5$ & $49 \pm 7$ & 0.54 \\
\hline DES & $19(37)$ & $16(48)$ & 0.36 \\
\hline BMS & $17(33)$ & $10(30)$ & 0.81 \\
\hline Unknown stent type & $15(30)$ & $7(22)$ & 0.45 \\
\hline Bifurcation lesion & $9(18)$ & $3(9)$ & 0.34 \\
\hline \multicolumn{4}{|l|}{ Culprit ST lesion } \\
\hline LAD & $22(43)$ & $14(42)$ & 1.00 \\
\hline $\mathrm{LCx}$ & $12(23.5)$ & $2(6)$ & 0.04 \\
\hline RCA & $15(30)$ & $15(45)$ & 0.16 \\
\hline Graft & 0 & $1(3)$ & 0.39 \\
\hline
\end{tabular}

Variables are $n(\%)$ or mean \pm standard deviation. $p<0.05$ is considered significant. CKD, chronic kidney disease; ST, stent thrombosis; DAPT, dual antiplatelet therapy; LVEF, left ventricular ejection fraction; DES, drug-eluting stent; BMS, bare-metal stent; LAD, left anterior descending artery; LCx, left circumflex artery; RCA, right coronary artery.

female gender, and had more comorbidities, a higher rate of previous myocardial infarction, a lower LVEF and more severe extent of CAD, and higher C-reactive protein levels at presentation.

\section{Chronic Kidney Disease and Stent Thrombosis}

STEMI patients having CKD were more likely to demonstrate ST in the primary PCI $(33 / 448,7 \%)$ compared to patients without CKD $(51 / 1,274,0.5 \%, p<0.001)$. No significant difference was found in the rate of ST between patients with stage 3 or stage 4/5 CKD (7 vs. $9 \%, p=0.365$ ). In the subgroup analysis of ST patients stratified in accordance to presence of CKD (Table 2), no major differences were observed in the rate of early or late ST, DAPT treatment at presentation, LVEF, original stent type (drug-eluting stent or bare-metal stent), bifurcation lesions, or culprit lesion site. In contrast, a higher rate of female patients with CKD compared with those without CKD was observed ( $23 \mathrm{vs.} 8 \%, p=0.04$ ), as well as a higher rate of left circumflex stent thrombosis in ST patients without CKD in comparison to those with CKD (23.5 vs. $6 \%, p=0.04)$.

\section{Chronic Kidney Disease, Stent Thrombosis, and Mortality}

Over a mean period of 1,170 \pm 784 days (range 1-2,736), 114 (6.6\%) patients of the entire cohort died. Figure 1 shows the Kaplan-Meier survival curve for long-term survival according to the presence or absence of CKD with or without ST. Mortality was significantly higher among those with CKD $(79 / 448,17.6 \%)$ compared to those without CKD $(35 / 1,274$, $2.7 \%, p<0.001$ ). Among patients without CKD, the presence of ST had no significant impact on long-term mortality ( 4.0 vs. $2.7 \%, p=0.66$ ). Similarly, among patients with CKD, the presence of ST had no significant impact on long-term mortality (26 vs. $16 \%, p=0.15$; Fig. 1). In the Cox regression model for all-cause mortality in all patients presenting with STEMI (Table 3), CKD emerged as an independent predictor of mortality reaching a hazard ratio of 


\section{CardioRenal Medicine}

Fig. 1. Cumulative long-term survival after a STEMI event in CKD and no-CKD patients with or without ST. Mortality was significantly higher among those with CKD compared to those without CKD $(p<0.001)$. The presence of ST at presentation did not alter longterm mortality in both CKD and no-CKD patients ( $p=0.15$ and $p=$ 0.66 , respectively). CKD, chronic kidney disease; ST, stent thrombosis.

Table 3. Cox regression model for predictors of long-term mortality in all patients presenting with ST-segment elevation myocardial infarction

\begin{tabular}{l|l}
\hline Cardiorenal Med 2017;7:150-157 \\
\hline DOI: 10.1159/000455905 & $\begin{array}{l}\text { @ 2017 S. Karger AG, Basel } \\
\text { www.karger.com/crm }\end{array}$ \\
\hline
\end{tabular}

Margolis et al.: Prognostic Implications of Chronic Kidney Disease on Patients Presenting with STEMI with versus without Stent Thrombosis

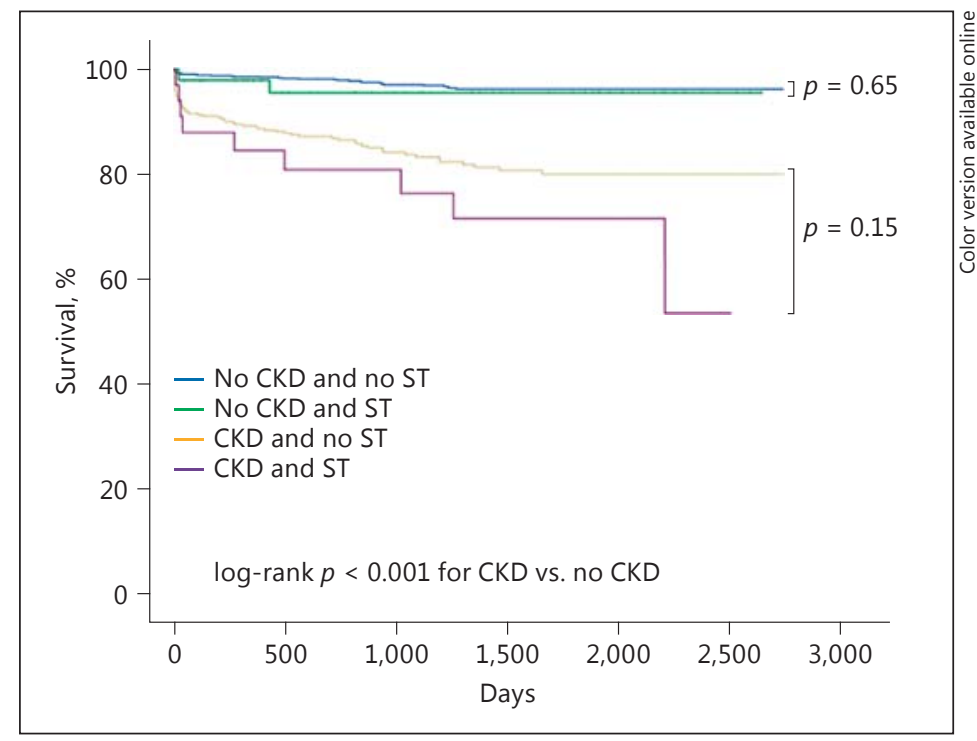

\begin{tabular}{llc}
\hline Variable & HR $(95 \% \mathrm{CI})$ & $p$ \\
\hline Age & $1.05(1.03-1.08)$ & $<0.001$ \\
Male gender & $1.30(0.84-2.01)$ & 0.24 \\
Diabetes mellitus & $1.28(0.83-1.97)$ & 0.27 \\
LVEF & $0.94(0.93-0.97)$ & $<0.001$ \\
HTN & $1.09(0.69-1.73)$ & 0.69 \\
CAD severity & $1.21(0.79-1.84)$ & 0.37 \\
ST & $1.51(0.75-3.03)$ & 0.24 \\
CKD stage 3 & $2.06(1.17-3.63)$ & 0.01 \\
CKD stage 4/5 & $2.94(1.16-7.48)$ & 0.02 \\
\hline
\end{tabular}

HR, hazard ratio; $\mathrm{CI}$, confidence interval; LVEF, left ventricular ejection fraction; HTN, hypertension; CAD, coronary artery disease; ST, stent thrombosis; CKD, chronic kidney disease.

2.04 (95\% confidence interval [CI] 1.17-3.56, $p=0.01)$. When using the same model, now according to CKD severity, the hazard ratio was 2.06 (95\% CI 1.17-3.63, $p=0.01$ ) for stage 3 CKD, and 2.94 (95\% CI 1.16-7.48, $p=0.02$ ) for stage 4/5 CKD. Other predictors of mortality were age and LVEF. Neither gender nor ST as covariates were significantly associated with long-term mortality.

\section{Discussion}

In this cohort of STEMI patients undergoing primary PCI, the presence of CKD was associated with a detrimental effect on long-term survival irrespective of the presence of ST. Moreover, ST by itself did not emerge as a predictor of long-term mortality in a multivariable model.

CKD has been associated with an increased cardiovascular risk and a higher mortality rate among CAD patients. Possible explanations for this interaction include a greater propensity for risk factors such as older age, diabetes mellitus, and hypertension as observed 
Margolis et al.: Prognostic Implications of Chronic Kidney Disease on Patients

Presenting with STEMI with versus without Stent Thrombosis

in the current analysis (Table 1) in line with previous reports [1-3], as well as other factors such as oxidative stress, accelerated atherosclerosis, and a prothrombotic state [24].

In the present study, we observed a significantly higher rate of ST among CKD patients compared with those without CKD (7 vs. $4 \%, p<0.001$; Table 1 ). In previous reports, CKD was an independent risk factor for ST [9-13]. Breet et al. [14] reported a higher rate of on-clopidogrel and on-aspirin platelet reactivity in patients with eGFR $<60 \mathrm{~mL} / \mathrm{min} / 1.73 \mathrm{~m}^{2}$ compared with those with higher eGFR. However, when adjusted for potential confounders, CKD was no longer significantly associated with a high on-treatment platelet reactivity. Indeed, in the current analysis, we found no difference in DAPT treatment between ST patients with or without CKD (33 vs. $27 \%$, respectively, $p=0.62$; Table 2 ). A possible explanation for these observations is that response to antiplatelet therapy is related to the comorbidities of the CKD patient rather than the CKD itself.

In the present analysis, in accordance with previous reports [4-7], CKD patients who presented with STEMI had a significantly higher long-term mortality compared with patients without CKD (17.6 vs. $2.7 \%$, respectively, $p<0.001$ ). The presence of ST at presentation did not alter long-term mortality in both CKD and no-CKD patients Moreover, in a multivariable analysis, CKD emerged as a predictor for long-term mortality while ST did not. In a singlecenter retrospective study aimed to evaluate the predictors of unfavorable clinical outcomes following an angiographically proved ST event, renal failure emerged as a predictor of definite ST and death [16]. However, in this report, the authors did not specify whether the renal failure was acute or chronic. Moreover, van Werkum et al. [17] conducted a multicenter registry in the Netherlands, whose purpose was to identify determinants associated with major adverse cardiac events after ST. CKD was not identified as an important clinical predictor of poor outcomes after an ST event in their analysis. As the data about the prognostic determinants after an ST event to date is scarce and derived from retrospective studies only (including the current study), it appears that prospective studies are in need to clarify the role of CKD in an ST event.

Our findings suggest that CKD is an important predictor for long-term mortality after an ST event, rather than the ST event itself. On the other hand, in patients without CKD, an ST event does not seem to alter long-term mortality compared with a de novo thrombosis STEMI. These observations are contrary to a previous report [17] and may have some important clinical implications. CKD patients comprise a high-risk group among PCI-treated patients with a greater tendency for both bleeding [25] and thrombosis [9-13]. Thus, among patients who survived an ST event, those with CKD, despite a higher risk for bleeding [25], may still require more intense long-term clinical follow-up, possibly in conjugation with platelet function testing.

We acknowledge several important limitations of our study. First, this was a single-center retrospective and nonrandomized observational study and may have been subject to bias, even though we included consecutive patients and attempted to adjust for confounding factors using the multivariate regression model. Still, a survival bias may have occurred because out-of-hospital deaths as a result of ST were not included in our cohort. Second, as ST is an uncommon complication of PCI, our ST group of 83 patients (4.8\% of the entire study population) is consistent with previous reports [8-10], and thus could be underpowered to detect differences between the ST subgroups. Third, only serum creatinine level at admission was used to assess basic renal function as previously done $[6,7]$, which might be a source of error as the MDRD equation requires a stable creatinine level which might not be the case in STEMI patients. Fourth, we were not able to retrieve data about the PCI associated with the initial stent implantation such as stent type or length in the ST subgroup. However, predictors of ST have been well studied before [10-13], and this study focused on the potential prognostic implications of the interaction between CKD and ST rather than on ST risk factors. 
Margolis et al.: Prognostic Implications of Chronic Kidney Disease on Patients

Presenting with STEMI with versus without Stent Thrombosis

In conclusion, in the present analysis, we have found that CKD was a predictor of longterm mortality in patients presenting with STEMI irrespective of the presence of ST.

\section{Statement of Ethics}

All subjects (or their parents or guardians) have given their informed written consent. The study protocol was approved by the local institutional ethics committee.

\section{Disclosure Statement}

The authors have no conflicts of interest to declare.

\section{References}

1 Sarnak MJ, Levey AS, Schoolwerth AC, Coresh J, Culleton B, Hamm LL, McCullough PA, Kasiske BL, Kelepouris E, Klag MJ, Parfrey P, Pfeffer M, Raij L, Spinosa DJ, Wilson PW; American Heart Association Councils on Kidney in Cardiovascular Disease, High Blood Pressure Research, Clinical Cardiology, and Epidemiology and Prevention: Kidney disease as a risk factor for development of cardiovascular disease: a statement from the American Heart Association Councils on Kidney in Cardiovascular Disease, High Blood Pressure Research, Clinical Cardiology, and Epidemiology and Prevention. Circulation 2003;108:2154-2169.

2 Ix JH, Shlipak MG, Liu HH, Schiller NB, Whooley MA: Association between renal insufficiency and inducible ischemia in patients with coronary artery disease: the heart and soul study. J Am Soc Nephrol 2003;14:32333238.

3 Muntner P, He J, Hamm L, Loria C, Whelton PK: Renal insufficiency and subsequent death resulting from cardiovascular disease in the United States. J Am Soc Nephrol 2002;13:745-753.

4 Yamaguchi J, Kasanuki H, Ishii Y, Yagi M, Ogawa H, Fujii SY, Koganei H, Okada H, Kimura H, Horie T, Haze K, Sumiyoshi T, Honda T; HIJC Study Group: Prognostic significance of serum creatinine concentration for in-hospital mortality in patients with acute myocardial infarction who underwent successful primary percutaneous coronary intervention (from the Heart Institute of Japan Acute Myocardial Infarction [HIJAMI] Registry). Am J Cardiol 2004;93:1526-1528.

5 Bae EH, Lim SY, Cho KH, Choi JS, Kim CS, Park JW, Ma SK, Jeong MH, Kim SW: GFR and cardiovascular outcomes after acute myocardial infarction: results from the Korea Acute Myocardial Infarction Registry. Am J Kidney Dis 2012;59:795-802.

6 Shlipak MG, Heidenreich PA, Noguchi H, Chertow GM, Browner WS, McClellan MB: Association of renal insufficiency with treatment and outcomes after myocardial infarction in elderly patients. Ann Intern Med 2002; 137:555-562.

7 Wright RS, Reeder GS, Herzog CA, Albright RC, Williams BA, Dvorak DL, Miller WL, Murphy JG, Kopecky SL, Jaffe AS: Acute myocardial infarction and renal dysfunction: a high-risk combination. Ann Intern Med 2002; 137:563-570.

8 Ong AT, Hoye A, Aoki J, van Mieghem CA, Rodriguez Granillo GA, Sonnenschein K, Regar E, McFadden EP, Sianos G, van der Giessen WJ, de Jaegere PP, de Feyter P, van Domburg RT, Serruys PW: Thirty-day incidence and six-month clinical outcome of thrombotic stent occlusion after bare-metal, sirolimus, or paclitaxel stent implantation. J Am Coll Cardiol 2005;45:947-953.

9 Iakovou I, Schmidt T, Bonizzoni E, Ge L, Sangiorgi GM, Stankovic G, Airoldi F, Chieffo A, Montorfano M, Carlino M, Michev I, Corvaja N, Briguori C, Gerckens U, Grube E, Colombo A: Incidence, predictors, and outcome of thrombosis after successful implantation of drug-eluting stents. JAMA 2005;293:2126-2130.

10 Lasala JM, Cox DA, Dobies D, Baran K, Bachinsky WB, Rogers EW, Breall JA, Lewis DH, Song A, Starzyk RM, Mascioli SR, Dawkins KD, Baim DS; ARRIVE 1 and ARRIVE 2 Participating Physicians: Drug-eluting stent thrombosis in routine clinical practice: two-year outcomes and predictors from the TAXUS ARRIVE registries. Circ Cardiovasc Interv 2009;2:285-293.

11 Zhu ZB, Zhang RY, Zhang Q, Zhang JS, Hu J, Yang ZK, Shen WF: Moderate-severe renal insufficiency is a risk factor for sirolimus-eluting stent thrombosis. The RIFT study. Cardiology 2009;112:191-199.

12 Machecourt J, Danchin N, Lablanche JM, Fauvel JM, Bonnet JL, Marliere S, Foote A, Quesada JL, Eltchaninoff H, Vanzetto G; EVASTENT Investigators: Risk factors for stent thrombosis after implantation of sirolimus-eluting stents in diabetic and nondiabetic patients: the EVASTENT Matched-Cohort Registry. J Am Coll Cardiol 2007; 50:501-508

13 Park DW, Park SW, Park KH, Lee BK, Kim YH, Lee CW, Hong MK, Kim JJ, Park SJ: Frequency of and risk factors for stent thrombosis after drug-eluting stent implantation during long-term follow-up. Am J Cardiol 2006;98: 352-356. 
Margolis et al.: Prognostic Implications of Chronic Kidney Disease on Patients Presenting with STEMI with versus without Stent Thrombosis

14 Breet NJ, de Jong C, Bos WJ, van Werkum JW, Bouman HJ, Kelder JC, Bergmeijer TO, Zijlstra F, Hackeng CM, Ten Berg JM: The impact of renal function on platelet reactivity and clinical outcome in patients undergoing percutaneous coronary intervention with stenting. Thromb Haemost 2014;112:1174-1181.

15 Angiolillo DJ, Bernardo E, Capodanno D, Vivas D, Sabate M, Ferreiro JL, Ueno M, Jimenez-Quevedo P, Alfonso F, Bass TA, Macaya C, Fernandez-Ortiz A: Impact of chronic kidney disease on platelet function profiles in diabetes mellitus patients with coronary artery disease taking dual antiplatelet therapy. J Am Coll Cardiol 2010;55:1139-1146.

16 Almalla M, Schroder J, Hennings V, Marx N, Hoffmann R: Long-term outcome after angiographically proven coronary stent thrombosis. Am J Cardiol 2013;111:1289-1294.

17 van Werkum JW, Heestermans AA, de Korte FI, Kelder JC, Suttorp MJ, Rensing BJ, Zwart B, Brueren BR, Koolen JJ, Dambrink JH, van't Hof AW, Verheugt FW, ten Berg JM: Long-term clinical outcome after a first angiographically confirmed coronary stent thrombosis: an analysis of 431 cases. Circulation 2009;119:828-834.

18 Shacham Y, Leshem-Rubinow E, Gal-Oz A, Arbel Y, Keren G, Roth A, Steinvil A: Acute cardio-renal syndrome as a cause for renal deterioration among myocardial infarction patients treated with primary percutaneous intervention. Can J Cardiol 2015;31:1240-1244.

19 Shacham Y, Leshem-Rubinow E, Steinvil A, Assa EB, Keren G, Roth A, Arbel Y: Renal impairment according to acute kidney injury network criteria among ST elevation myocardial infarction patients undergoing primary percutaneous intervention: a retrospective observational study. Clin Res Cardiol 2014;103:525-532.

20 O'Gara PT, Kushner FG, Ascheim DD, Casey DE, Jr., Chung MK, de Lemos JA, Ettinger SM, Fang JC, Fesmire FM, Franklin BA, Granger CB, Krumholz HM, Linderbaum JA, Morrow DA, Newby LK, Ornato JP, Ou N, Radford MJ, Tamis-Holland JE, Tommaso JE, Tracy CM, Woo YJ, Zhao DX; CF/AHA Task Force: 2013 ACCF/AHA guideline for the management of ST-elevation myocardial infarction: executive summary: a report of the American College of Cardiology Foundation/American Heart Association Task Force on Practice Guidelines. Circulation 2013;127:529-555.

21 Levey AS, Bosch JP, Lewis JB, Greene T, Rogers N, Roth D: A more accurate method to estimate glomerular filtration rate from serum creatinine: a new prediction equation. Modification of Diet in Renal Disease Study Group. Ann Intern Med 1999;130:461-470.

22 National Kidney Foundation: K/DOQI clinical practice guidelines for chronic kidney disease: evaluation, classification, and stratification. Am J Kidney Dis 2002;39:S1-S266.

23 Cutlip DE, Windecker S, Mehran R, Boam A, Cohen DJ, van Es GA, Steg PG, Morel MA, Mauri L, Vranckx P, McFadden E, Lansky A, Hamon M, Krucoff MW, Serruys PW; Academic Research Consortium: Clinical end points in coronary stent trials: a case for standardized definitions. Circulation 2007;115:2344-2351.

24 Best PJ, Lennon R, Ting HH, Bell MR, Rihal CS, Holmes DR, Berger PB: The impact of renal insufficiency on clinical outcomes in patients undergoing percutaneous coronary interventions. J Am Coll Cardiol 2002;39: 1113-1119.

25 Gaspari F, Vigano G, Orisio S, Bonati M, Livio M, Remuzzi G: Aspirin prolongs bleeding time in uremia by a mechanism distinct from platelet cyclooxygenase inhibition. J Clin Invest 1987;79:1788-1797. 